\title{
EVALUATION OF THE FRACTURE RESISTANCE OF THREE DIFFERENT IMPLANT SUPPORTED OVERDENTURE BASE MATERIALS
}

\author{
Nada Sherin El Khourazaty*
}

\begin{abstract}
Objectives: The objective of this study was to evaluate and compare the effect of incorporating $5 \%$ zirconium powder to conventional acrylic resin and injection molded thermoplastic resin denture bases regarding the fracture resistance.
\end{abstract}

Materials and Methods: The study was performed on acrylic models of a completely edentulous mandibular arch with two implants installed bilaterally at the canine areas. Fifteen duplicates of the model were done on which fabrication of three types of dentures was carried out. Group 1 conventional acrylic resin heat cured PMMA, group 2 conventional acrylic resin heat cured PMMA $+5 \%$ zirconium powder and group 3 thermopress flexible polymeric $+5^{\circ}$ zirconium powder. Fracture test was done using the universal testing machine. The load required to fracture the denture bases was recorded in Newton. The data was collected and tabulated for statistical analysis.

Results: There was a statistically significant difference between the 3 types of denture bases regarding the fracture resistance in which the highest mean value of 4941.20 was recorded with the conventional acrylic denture base reinforced with $5 \%$ zirconium powder followed by bre.flex flexible therompress polyamide reinforced with $\mathrm{ZrO} 2$ then the conventional acrylic resin which presented the lowest mean value of 1336.00 .

Conclusion: The fracture resistance of the conventional acrylic resin denture base after reinforcement was the highest amongst the tested materials which renders it as a good alternative to conventional acrylic denture base for construction of mandibular implant supported over denture.

Acrylic resins denture base; over denture; denture fracture; mechanical properties; fracture resistance

KEYWORDS: Acrylic resins denture base; over denture; denture fracture; mechanical properties; fracture resistance

\footnotetext{
* Associate Professor Prosthodontics, Faculty of Oral and Dental Medicine, Cairo University
} 


\section{INTRODUCTION}

Prosthodontic rehabilitation of completely edentulous patients is a common procedure that clinicians approach in their daily practice. The use of implant supported overdentures for replacing missing teeth proved to be a safe, reliable technique and the implant prosthetic materials available enhance the chance of having long term clinical success. (Wang et al., 2016)

Among the most common prosthetic complications that occur with implant supported overdenture is the failure or fracture of the denture base material. (Gonda et al., 2010) Denture bases are prone to fracture after clinical use, impact failure extra orally and flexure fatigue failure intraorally are two most important causes of fracture of denture base. (Chand et al., 2011) Reinforcement of the denture base over the implants is recommended to increase fracture resistance.(Elsyad et al., 2013)

Polymethyl methacrylate (PMMA) is the most common denture base material used due to its biocompatibility, esthetics, accurate fit, stability in the oral environment, ease of construction and adjustment, decreased cost, and possibility of repair. (Meng \& Latta, 2005) (Nejatian et al., 2006) On the other hand it was found that its fracture resistance is not satisfactory. (Nejatian et al., 2006)

Thermoplastic denture base resin material are being utilized extensively as an alternative to conventional acrylic because of their different physical and mechanical properties. They have a lower elastic modulus but high elasticity and fracture resistance. Therefore, these resins can be made thinner and lighter compared to conventional heat curing acrylic resins, thereby improving wearability. (Song et al., 2019) The Polyamide resins exhibits high flexibility, physical strength, heat and chemical re- sistance and the exceedingly rare allergic response. (A Mahmoud et al., 2018)

It has been shown that acrylic resin and thermoplastic denture base resins can be strengthened through the addition of a structural component of different size distributed in the acrylic matrix, thus forming a more composite structure. (Panyayong et al., 2002) (Abdul-Majeed \& Hummudi, 2019)

$\mathrm{ZrO} 2$ is a hard white amorphous powder that is obtained from zirconium which is found naturally and produced by a thermal process. $\mathrm{ZrO} 2$ is a material that is very resistance to crack propagation and has premium mechanical properties with high strength, fracture toughness and high thermal expansion. (Asar et al., 2013) Several studies showed improved strength, fatigue, hardness and compression with the addition of $\mathrm{ZrO} 2$ nanoparticles to PMMA.(AlKaram \& Majeed, 2019) (Bangera et al., 2020)

\section{METHODOLOGY:}

\section{Model fabrication and implant installation}

The study was performed on an epoxy model ${ }^{*}$ duplicated from a completely edentulous mandibular arch. The model's dimensions of the ridge were $5 \mathrm{~mm}$ in width and $13 \mathrm{~mm}$ in length at the canine areas to accommodate a dummy implant of $3.7 \mathrm{~mm}$ diameter and $12 \mathrm{~mm}$ length ${ }^{* * *}$ which were placed in the canine areas, one on each side. A waxed-up trial denture was used to guide the placement of the implants in the correct position. Implant parallelism was achieved using a milling machine.*** Drilling sequence was commenced until the implants were flushed with the crest of the ridge of the acrylic resin model. Self-cured acrylic resin was used to attach the implants to the models in a manner resembling osseointegration. Figure 1.

\footnotetext{
* Clear heat cured acrylic resin, Acrostone, Egypt.

** Osteoseal dental implants, California, USA

*** Bego Bremer Goldschagerei Wihl. Herbst, Bremen, Germany
} 


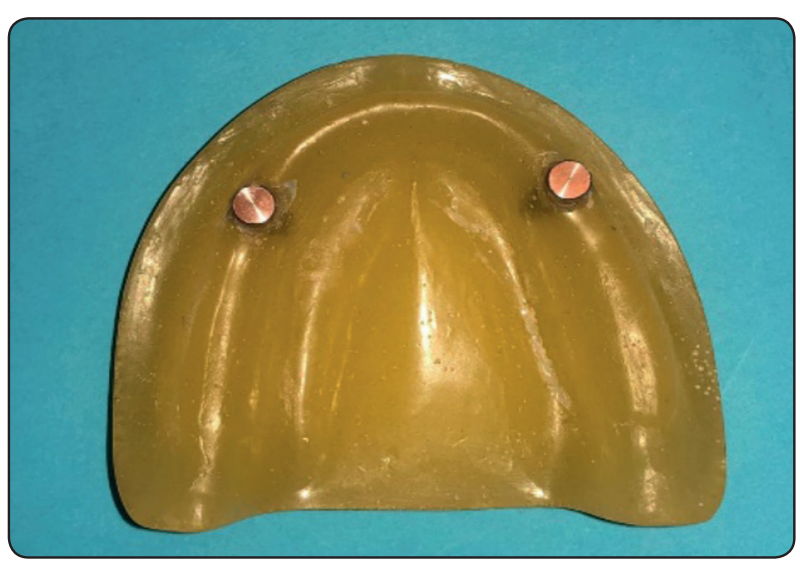

Fig. (1) The fabricated model with the implants.

The epoxy model was duplicated 15 times in dental stone after creating indices in the base to facilitate the construction of putty index later. These duplicate models were used to fabricate 5 identical dentures in each group. To ensure that the dentures have identical dimensions; an even thickness of base plate wax was adapted on one of the duplicate casts then teeth were set according to the standard guidelines followed by waxing up. A rubber base index was then made for the polished surface and the teeth that facilitated duplicating the remaining four dentures with the same denture base thickness and teeth setting.

The groups were divided into group 1 conventional acrylic resin Acrostone heat cured PMMA* group 2 conventional acrylic resin Acrostone heat cured PMMA $+5 \%$ zirconium powder and group 3 thermopress flexible polymeric $^{* *}+5 \%$ zirconium powder.

The zirconium oxide filler, PMMA and the thermopress were pre-weighed to ensure a filler concentration of $5 \%$ by weight. Filler particles were treated with $1 \mathrm{wt} \%$ of silane coupling agent (Dentsply, India) before the mix. Mixing and blending were done to obtain a consistent and homogenous mix before manipulation of the materials in the conventional manner.

\section{Fracture resistance testing}

All the samples were individually mounted on a computer-controlled material universal testing machine ${ }^{* * *}$ with a loadcell of $5 \mathrm{kN}$ and data were recorded using a computer software. ${ }^{* * * *}$ Figure 1 the samples were secured to the lower fixed compartment of the testing machine by tightening. Fracture test was done by compressive mode of load applied occlusally using inverted t-shaped metallic load applicator fixed to the upper part of the machine. The applicator was positioned over the central fossae of the 1st molars bilaterally to achieve homogenous stress distribution. The upper movable compartment of testing machine moved at crosshead speed of $5 \mathrm{~mm} / \mathrm{min}$. The load at failure manifested by an audible crack and confirmed by a sharp drop at load-deflection curve recorded

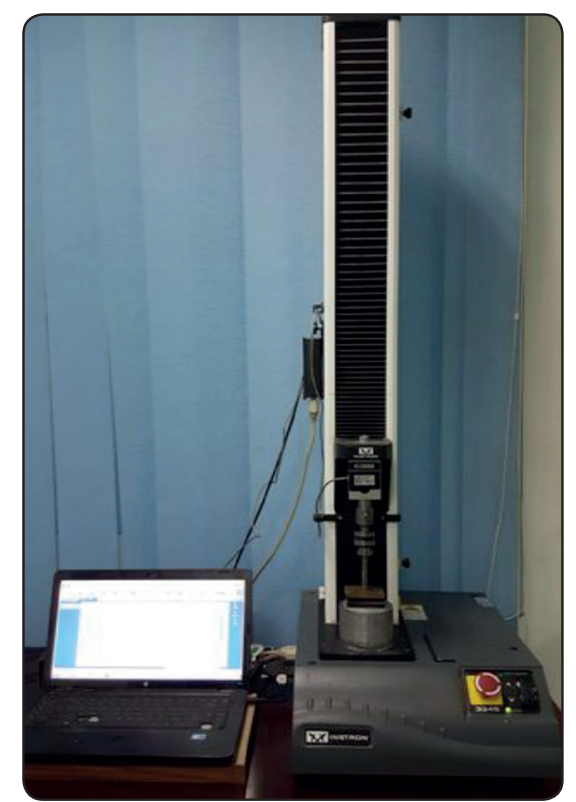

Fig. (2): Universal testing machine and the computer software.

\footnotetext{
* Acrostone heat cured PMMA (Cross linked heat cured pink denture base material, Acrostone manufacture, Egypt, Licensed by WHW, England

** bre. flex 2nd edition (Bredent, 5400F605, GmbH \& Co.KG. Weissenhorner Str. 2, 89250 Senden, Germany

*** Model 3345; Instron Industrial Products, Norwood, MA, USA

**** Bluehill Lite Software from Instron®.
} 
using the computer software. Figure 3,4,5. The load required to fracture the denture bases was recorded in Newton. The data was collected and tabulated for statistical analysis.

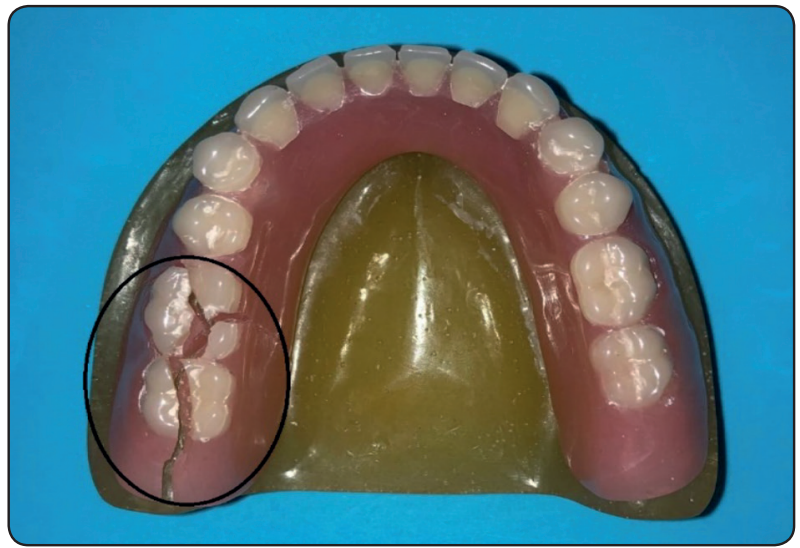

Fig. (3): Conventional acrylic resin Acrostone heat cured PMMA.

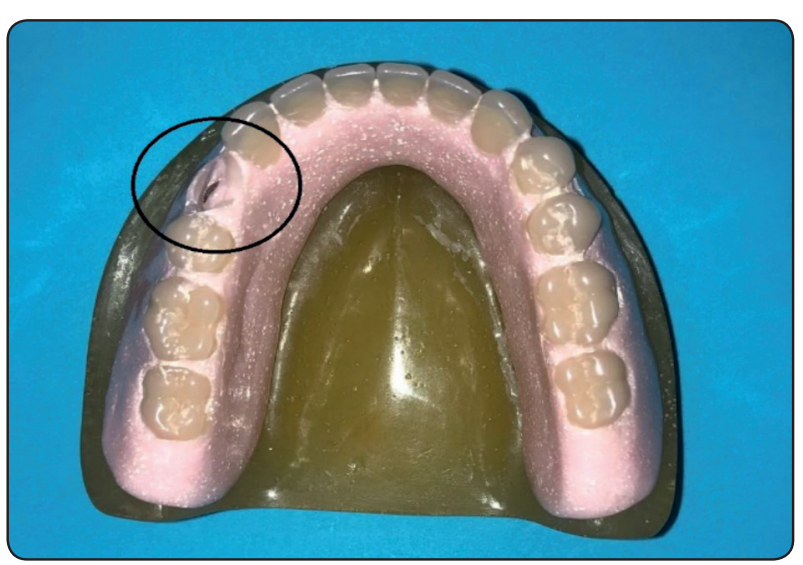

Fig. (4): Conventional acrylic resin Acrostone heat cured PMMA $+5 \%$ zirconium powder

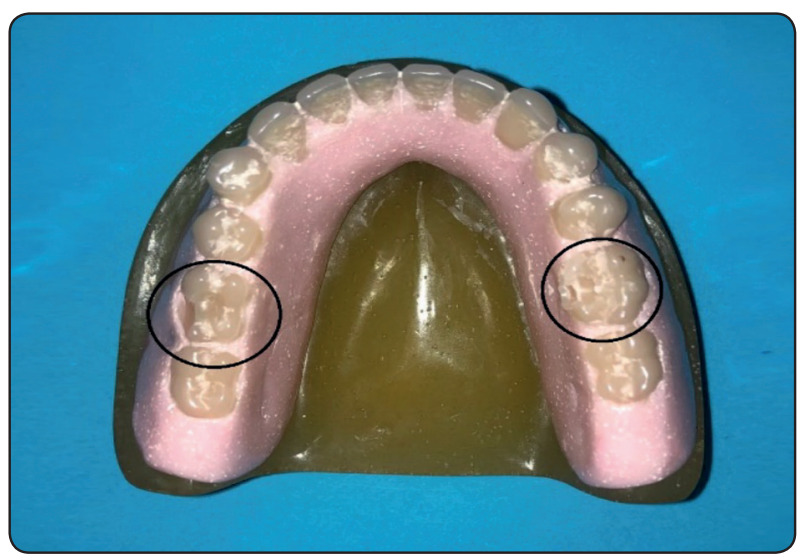

Fig. (5): Thermopress flexible polymeric $+5 \%$ zirconium powder.

\section{Statistical analysis}

The mean and standard deviation values in this study were calculated for each group in each test. The data were explored for normality using Kolmogorov-Smirnov and Shapiro-Wilk tests and showed parametric (normal) distribution. One-way ANOVA followed by Tukey post hoc test was used to compare between more than two groups in nonrelated samples. The significance level was set at $\mathrm{P} \leq 0.05$. Statistical analysis was performed with IBM ${ }^{\circledR}$ SPSS ${ }^{\circledR}$ Statistics Version 20 for Windows.

\section{RESULTS}

The results of this study showed that there was a statistically significant difference between the three types of denture base materials regarding the fracture resistance in which the highest mean value of 4941.20 was recorded with the conventional acrylic denture base reinforced with $5 \%$ zirconium powder followed by bre.flex flexible therompress polyamide reinforced with $\mathrm{ZrO} 2$ then the conventional PMMA which presented the lowest mean value of 1336.00 .

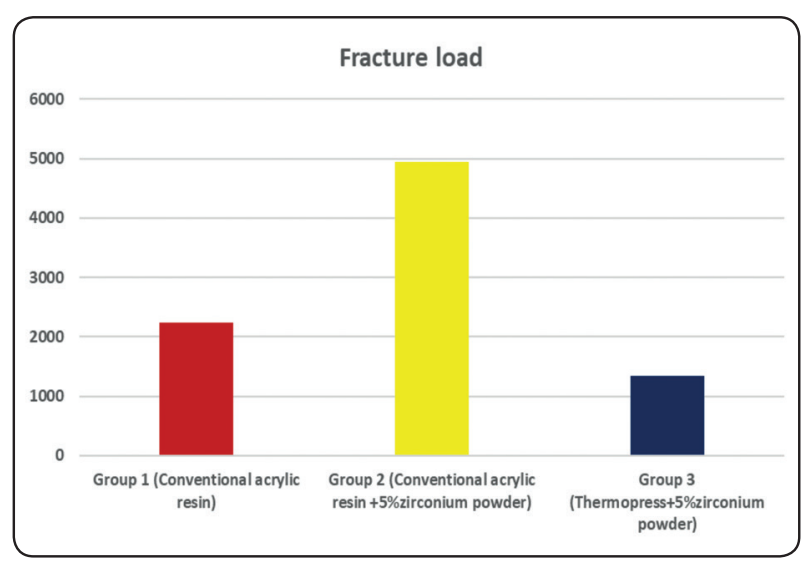

Fig. (6): Bar chart representing fracture load for the three groups. 


\section{DISCUSSION}

Literature search revealed that the addition of varying quantities of metal fillers such as powdered silver, copper, and aluminum into PMMA at various concentrations not only gives it the benefit of increased strength and improved thermal conductivity, but also decreases the polymerization shrinkage, reduces the warpage, makes the material radiopaque and inhibits the growth of bacteria over the denture surface. The major disadvantage of adding metal fillers however is its compromised esthetics. (Ellakwa et al., 2008) (Al-Karam \& Majeed, 2019) (Shukla \& Seal, 2003) (Asopa et al., 2015)

The inclusion of zirconia in various dental materials has been studied and it was found to be biocompatible and had significant beneficial effects on the mechanical properties. (Ayad et al., 2008) (Korkmaz et al., 2005) (Ahmed Omran Alhareb \& Zainal Arifin Ahmad, 2011) Also, the white color of zirconia powder does not compromise the esthetics unlike its metal filler equivalents like aluminum, copper or silver. (Asopa et al., 2015) Incorporation of $\mathrm{ZrO} 2$ nanoparticles into PMMA resin significantly improved flexural strength, flexural modulus, fracture toughness and surface hardness, with an optimum concentration of 3-5 wt.\% zirconia. (Zidan et al., 2019).

Good quality adhesion and dispersion homogeneity of nano-ZrO2 with the resin matrix effectively improve the properties of the polymer/nanoparticles composite. Therefore, surface modification of nanoparticles with a saline coupling agent might lessen the aggregation of nano- $\mathrm{ZrO} 2$ and then enhance its compatibility with the polymer, which may result in the improvement of composite properties. (Sarac et al., 2005)

The results of this study revealed that the values of maximum fracture resistance were higher in the conventional acrylic resin reinforced with $5 \% \mathrm{ZrO} 2$ group and it was much higher than those of the bre. flex flexible therompress polyamide reinforced with $\mathrm{ZrO} 2$ group. This could be attributed to the addition of $\mathrm{ZrO} 2$ powder and the chemical properties of polyamide, enabling it to better absorb forces which is different from those of the conventional PMMA. This comes in agreement with previously conducted stuies. (Nejatian et al., 2006) (Gad et al., 2016) (Soygun et al., 2013)

Also, the results of this study showed that bre. flex flexible therompress polyamide reinforced with $\mathrm{ZrO} 2$ has higher fracture resistance than the conventional acrylic but significantly less than that of the conventional acrylic reinforced with $5 \% \mathrm{ZrO} 2$ this comes in contrast to another study conducted by (A Mahmoud et al., 2018) in which the reinforcement of the theropress with gold nanoparticles showed higher fracture resistance values than the conventional acrylic reinforced with the same material. This might be due to the difference in the physical and mechanical properties of gold and zirconium.

\section{CONCLUSION}

Within the limitations of this in vitro study, the incorporation of $5 \% \mathrm{ZrO} 2$ into acrylic resin and thermopress flexible polymeric denture base materials improved the fracture resistance. The high fracture resistance of the conventional acrylic resin denture bases after reinforcement renders it as a good alternative to conventional acrylic denture base for construction of mandibular implant supported over denture.

\section{REFERENCES}

- A Mahmoud, T., E Sanad, M., \& I Seif-ElNasr, M. (2018). Effect of nano-gold reinforcement of polymethyl methacrylate and flexible polyamide denture base materials on impact strength\#. Al-Azhar Journal of Dental Science, 21(1), 47-50. https://doi.org/10.21608/ajdsm.2020.71474

- $\quad$ Abdul-Majeed,Z.E., \& Hummudi, I. M. (2019). Evaluation the Effect of Fibers Addition on Mechanical Properties of Flexible Acrylic Resin. Iraqi Dental Journal, 41(1), 8-31. https://doi.org/10.46466/idj.v41i1.180

- $\quad$ Ahmed Omran Alhareb, \& Zainal Arifin Ahmad. (2011). Effect of $\mathrm{A} 12 \mathrm{O} 3 / \mathrm{ZrO} 2$ reinforcement on the mechanical properties of PMMA denture base. Journal of Reinforced Plastics and Composites, 30(1), 86-93. https://doi. org/10.1177/0731684410379511 
- Al-Karam, L. Q., \& Majeed, S. M. (2019). Evaluation the mechanical properties of PMMA / ZrO2 nanoparticles for dental application. International Journal of Research in Pharmaceutical Sciences, 10(3), 2002-2007. https://doi. org/10.26452/ijrps.v10i3.1409

- $\quad$ Asar, N. V., Albayrak, H., Korkmaz, T., \& Turkyilmaz, I. (2013). Influence of various metal oxides on mechanical and physical properties of heat-cured polymethyl methacrylate denture base resins. The Journal of Advanced Prosthodontics, 5(3), 241. https://doi.org/10.4047/jap.2013.5.3.241

- $\quad$ Asopa, V., Suresh, S., Khandelwal, M., Sharma, V., Asopa, S. S., \& Kaira, L. S. (2015). A comparative evaluation of properties of zirconia reinforced high impact acrylic resin with that of high impact acrylic resin. The Saudi Journal for Dental Research, 6(2), 146-151. https://doi.org/10.1016/j. sjdr.2015.02.003

- Ayad, N., Badawi, M., \& Fatah, A. (2008). Effect of reinforcement of high-impact acrylic resin with zirconia on some physical and mechanical properties. Rev. Clín. Pesq. Odontol. (Impr.). https://doi.org/10.7213/aor.v4i3.23218

- Bangera, M. K., Kotian, R., \& N, R. (2020). Effect of titanium dioxide nanoparticle reinforcement on flexural strength of denture base resin: A systematic review and meta-analysis. In Japanese Dental Science Review (Vol. 56, Issue 1, pp. 68-76). Elsevier Ltd. https://doi.org/10.1016/j. jdsr.2020.01.001

- $\quad$ Chand, P., Patel, C. B. S., Singh, B. P., Singh, R. D., \& Singh, K. (2011). Mechanical properties of denture base resins: An evaluation. Indian Journal of Dental Research, 22(1), 200-204. https://doi.org/10.4103/0970-9290.79997

- $\quad$ Ellakwa, A. E., Morsy, M. A., \& El-Sheikh, A. M. (2008). Effect of aluminum oxide addition on the flexural strength and thermal diffusivity of heat-polymerized acrylic resin. Journal of Prosthodontics, 17(6), 439-444. https://doi. org/10.1111/j.1532-849X.2008.00318.x

- $\quad$ Elsyad, M. A., El-Waseef, F. A., Al-Mahdy, Y. F., \& Fouad, M. M. (2013). A comparison of mandibular denture base deformation with different impression techniques for implant overdentures. Clinical Oral Implants Research, 24(A100), 127-133. https://doi.org/10.1111/j.1600-0501.2011.02395.x

- Gad, M. M., Rahoma, A., Al-Thobity, A. M., \& ArRejaie, A. S. (2016). Influence of incorporation of $\mathrm{ZrO} 2$ nanoparticles on the repair strength of polymethyl methacrylate denture bases. International Journal of Nanomedicine, 11, 5633-5643. https://doi.org/10.2147/IJN.S120054

- Gonda, T., Maeda, Y., Walton, J. N., \& MacEntee, M. I. (2010). Fracture incidence in mandibular overdentures retained by one or two implants. Journal of Prosthetic Dentistry, 103(3), 178-181. https://doi.org/10.1016/S0022-3913(10)60026-1

- Korkmaz, T., Dǒan, A., \& Usanmaz, A. (2005). Dynamic mechanical analysis of provisional resin materials reinforced by metal oxides. Bio-Medical Materials and Engineering, 15(3), 179-188.

- $\quad$ Meng, T. R., \& Latta, M. A. (2005). Physical properties of four acrylic denture base resisns. Journal of Contemporary Dental Practice, 6(4), 93-100. https://doi.org/10.5005/ jcdp-6-4-93

- $\quad$ Nejatian, T., Johnson, A., \& Van Noort, R. (2006). Reinforcement of Denture Base Resin. Advances in Science and Technology, 49, 124-129. https://doi.org/10.4028/ www.scientific.net/AST.49.124

- $\quad$ Panyayong, W., Oshida, Y., Andres, C. J., Barco, T. M., Brown, D. T., \& Hovijitra, S. (2002). Reinforcement of acrylic resins for provisional fixed restorations. Part III: effects of addition of titania and zirconia mixtures on some mechanical and physical properties. Bio-Medical Materials and Engineering, 12(4), 353-366. http://www.ncbi. nlm.nih.gov/pubmed/12652030

- $\quad$ Sarac, Y. S., Sarac, D., Kulunk, T., \& Kulunk, S. (2005). The effect of chemical surface treatments of different denture base resins on the shear bond strength of denture repair. The Journal of Prosthetic Dentistry, 94(3), 259-266. https://doi.org/10.1016/j.prosdent.2005.05.024

- $\quad$ Shukla, S., \& Seal, S. (2003). Phase stabilization in nanocrystalline zirconia. Reviews on Advanced Materials Science, 5(2), 117-120.

- $\quad$ Song, S. Y., Kim, K. S., Lee, J. Y., \& Shin, S. W. (2019). Physical properties and color stability of injection-molded thermoplastic denture base resins. Journal of Advanced Prosthodontics, 11(1), 32-40. https://doi.org/10.4047/ jap.2019.11.1.32

- $\quad$ Soygun, K., Bolayir, G., \& Boztug,A. (2013). Mechanical and thermal properties of polyamide versus reinforced PMMA denture base materials. The Journal of Advanced Prosthodontics, 5(2), 153. https://doi.org/10.4047/jap.2013.5.2.153

- $\quad$ Wang, F., Monje, A., Huang, W., Zhang, Z., Wang, G., \& Wu, Y. (2016). Maxillary Four Implant-retained Overdentures via Locator® Attachment: Intermediate-term Results from a Retrospective Study. Clinical Implant Dentistry and Related Research, 18(3), 571-579. https://doi.org/10.1111/cid.12335

- $\quad$ Zidan, S., Silikas, N., Alhotan, A., Haider, J., \& Yates, J. (2019). Investigating the mechanical properties of $\mathrm{ZrO} 2$-impregnated PMMA nanocomposite for denture-based applications. Materials, 12(8). https://doi.org/10.3390/ma12081344 